\title{
AN INVESTIGATION OF THE ENERGY CONSUMPTION BY INFORMATION TECHNOLOGY EQUIPMENTS
}

\author{
Baharak Makki ${ }^{1}$ and Bahador Makki ${ }^{2}$ \\ ${ }^{1}$ Department of Engineering, Faculty of Engineering and Science, University of Agder, \\ N-4898 Grimstad, Norway \\ baharak.makki@uia.no \\ ${ }^{2}$ University of Bremen, Bibliothekstrasse 1, D-28357 Bremen, Germany \\ b.makki@uni-bremen. de
}

\begin{abstract}
The World Wide Web and the rise of servers and PC's data centers have become a major position in the overall power consumption of the world. In order to prevent global warming and ensuing disasters, already Internet-service providers, hosting providers on green power have changed. Even household energy suppliers offer green electricity from renewable energy such as wind, solar, biomass and hydro, which emits no carbon dioxide, to stand against global warming. Only a global change for the information technology can prevent the global-warming. The switch to renewable energy is the beginning of our future and must be pursued as well as the research and development in information and communication technology.
\end{abstract}

\section{KEYWORDS}

Renewable energy, web server, energy consumption

\section{INTRODUCTION}

The World Wide Web stands for worldwide network. In 1989, it was developed at Cern1. Initially intended only as a replacement system for scientific work, it has quickly developed into a system that is no longer possible to think in today's society.

Services to customers in the power industry are the most important goal. The flow of information is one of effective tools in the management of an organization to service the customers. If an organization wants to have an access to the correct and updated information, an attention and a serious effort should be paid to the development of information systems. Recently, energy consumption used by information technology (IT) equipment has become an interesting issue since the first ENERGY STAR specification for personal computers was released in the early 1990s [5]. The first detailed measurements of energy consumption for personal computers (PCs) together with an estimate of total electricity used by office equipment were reported in the late 1980s ([3], [7], [9], [10], [14]). Often, the first step towards harnessing the power consumption in data centers, is to understand how energy is used in the data center. Different types of analysis are using for measuring data center energy. Aspects of measurement are not only energy used by the equipment itself, but also are by the central data center equipment, including chillers and fans. Several research on estimate of power used by servers and data centers have been reported in the DOI : $10.5121 /$ ijcsit.2013.5203 
literature, see for instance [6], [12], [13], [15]. In [15], they are studying an estimate of the power by data storage systems and network equipment and aggregating data from IDC by server class and measured power data on a representative server for each class.

To best of our knowledge, few studies have been performed in this area. For instance, Ton and Fortenbery ([16]) extended the work done by Roth et al. 2004 on analysis of energy consumption by power suppliers. The developed analysis improves on the Roth et al. analysis for servers by estimating power use for servers in 2000, 2003, 2004, and 2005, and by using the latest IDC estimates of the installed base of servers in each class. Moreover, this analysis of energy consumption by power suppliers depends on power estimates from server powers used for the most popular server models in each size class.

Custom servers used by some large Internet companies (such as Google) are another important category of servers that may be represented in the IDC data. These are ordered directly from the manufacturer as personal computer motherboards but are then used as servers. For instance, it has been reported that Google owns about 450,000 servers worldwide [11]. It is not known whether all of these servers are the custom-designed units described above and how many are standard servers that would have fallen under the IDC 'volume server' category.

In General, the Structure of the enterprise systems and server market by server category is categorized as follows

- Volume Server Market $(<\$ 25,000)$

- Midrange Market $(\$ 25,000-\$ 249,999)$

- High-End Market (> \$500,000)

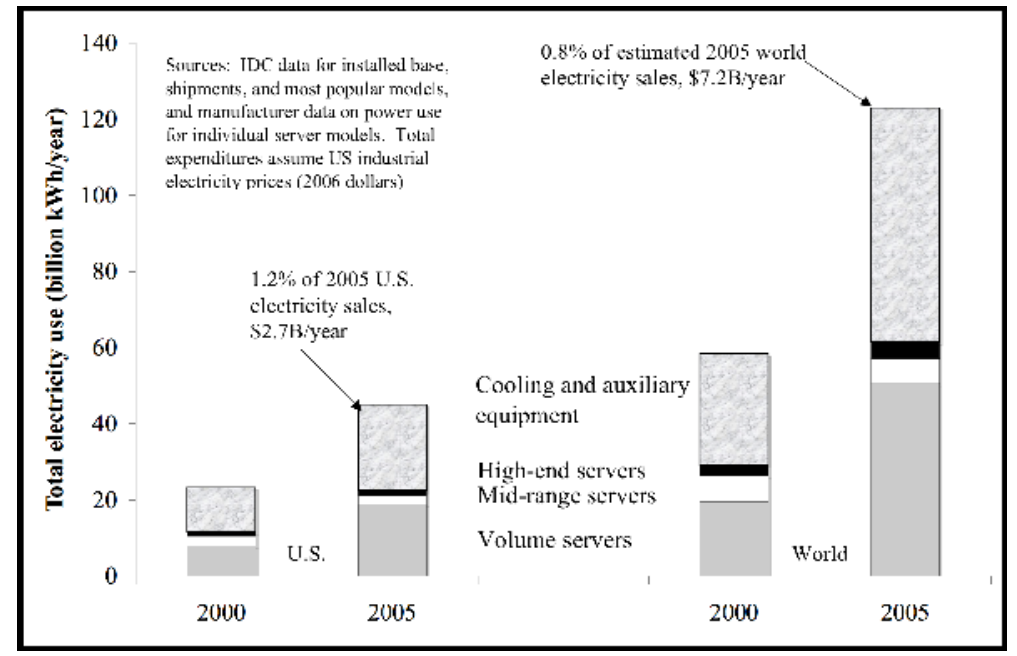

Figure 1: Total electricity use for servers in the U.S. and the world in 2000 and 2005 [8].

In Figure 1, in a period of 2000 to 2005, a total electricity used for servers are compared in USA and the rest of the world. This growth can be interpreted as the result of growth in the number of volume, mid-range or high-end servers. For instance, the total power used by servers was about $0.6 \%$ of total USA electricity consumption in 2005 without including cooling and auxiliary infrastructures. 
International Journal of Computer Science \& Information Technology (IJCSIT) Vol 5, No 2, April 2013

\section{PC USERS, INTERNET SERVICE PROVIDERS AND HOSTING COMPANIES}

End of the 90s the number of Internet users in Germany was estimated at about 5 million. 8 years later there were almost 43 million internet users thus an increase of 9 million per year. This rapid development has meant that huge data centers had to be built to the high demands of data resources which of PC users, Internet service providers and hosting companies were required to do [4].

A study by the Fraunhofer - Institute for Reliability and Micro Integration (ITM) and the Fraunhofer Institute for Systems and Innovation Research ISI has been studied for the Federal Ministry of Economics and Technology (BMW), the power consumption of information and communication technology in Germany extensively and is the result come to mind that 10.5 percent of total electricity consumption. By 2020, this power consumption expected to rise to 66.7 terawatt hours (TWh), representing an increase of 20 percent.

\subsection{The policy response}

Politicians and legislators have recognized the problem in time. Due to the continuing high electricity consumption which is still largely out of nuclear energy and coal energy has been covered, the road was opened, to generate electricity from environmentally friendly sources. The starting gun for this purpose was on 07.12.1990 successes with the Law on feeding electricity from renewable energy sources into the grid. After three to revision and expansion targets in the electricity sector by 2020 the share of renewable energies is $35 \%$ and even up to 2020 at least $50 \%$. It makes clear that the future means being outside without a huge burden on the current world.

\subsection{The cost of electricity production}

Figure 2 shows electricity flows in data centers. From the reliability point of view in data centers, it is important to design the electrical distribution system in a proper way. Therefore, the concept of energy losses should be taken into account because of numerous AC-DC conversions within data centers.

The cost of electricity generated includes the initial capital, return on investment, as well as the operation costs, fuel costs, and maintenance and service costs. This calculation does not include other costs associated with each type of plant, such as long distance connections to grids, balancing and reserve costs, etc [17]. The cost is normally presented in units of local currency per unit of electricity.

Since producing electricity from renewable sources cannot be a competitor for other sources of electricity in the market due to their higher production costs, society is in favor of an extended use of these technologies due to their benefits.

\section{THE IMPACT OF THE RENEWABLE ENERGY}

When discussing the impact of the renewable energy Act on the electricity price, one has to distinguish between a direct and an indirect effect [18]. 


\subsection{The direct effect}

In this effect, the impact of the renewable energy act on the electricity price can be assessed based on how much electricity from renewable energies is supplied.

\subsection{The indirect effect}

In addition to the direct price effect, there is a second, indirect effect, which will also lead to a decrease of spot market prices when additional electricity from renewable source enters the market. The latter will substitute electricity from conventional power plants.

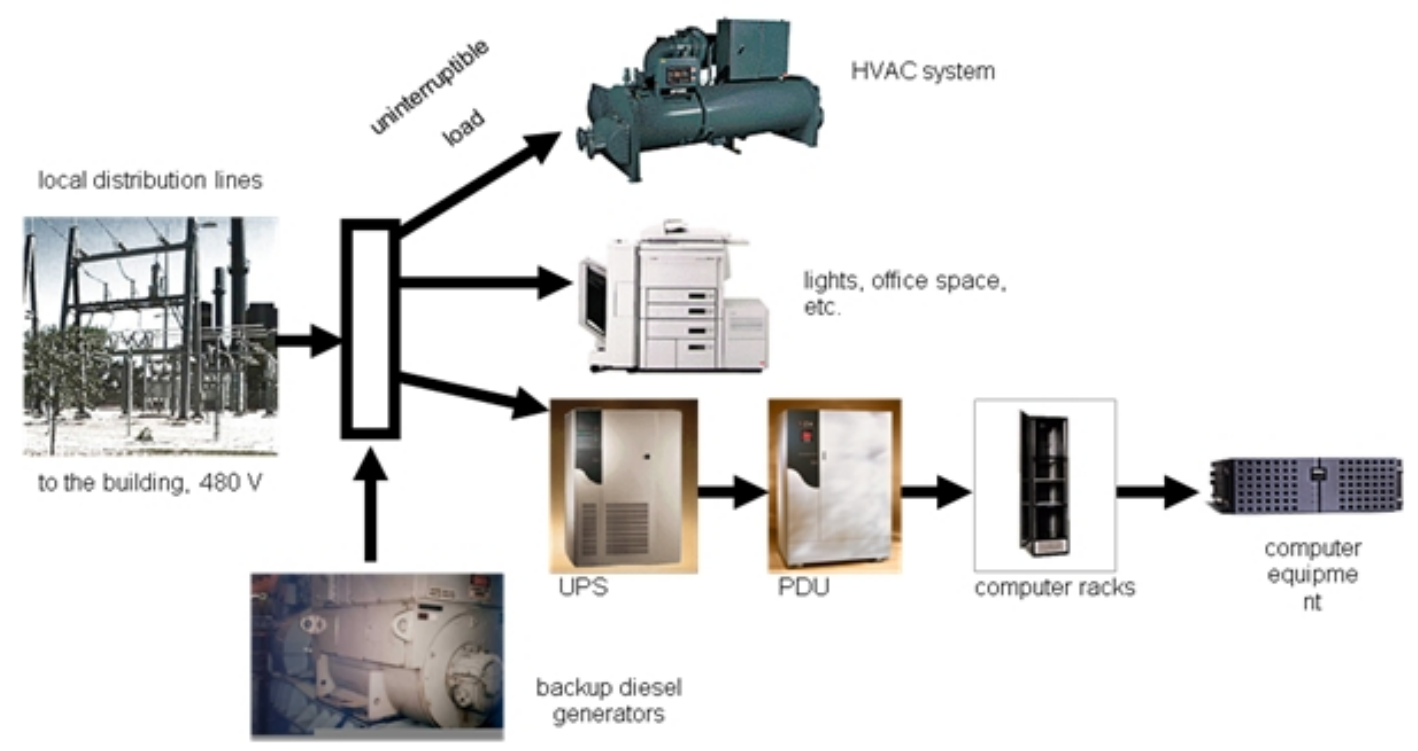

Figure 2: Electricity flows in data centers ${ }^{1}$.

\subsection{Transition from old to new energy}

Primary care-Worldwide offer customers to have clean electricity, which is produced from $100 \%$ renewable energy such as wind, solar, biomass and water. It is now up to companies to actually keep it in order to keep distance from the atomic to switch to green power. It is also clear that there are fluctuations during the transition period between the old Energy and the new energy.

\section{EXAMPLE}

In this section, we analyse the cost of electricity production for the conditions under which it makes sense to add wind turbines or a battery bank to a diesel power system using HOMER software. The system comprises two diesel generators, a $150 \mathrm{~kW}$ and a $75 \mathrm{~kW}$. The wind turbine under consideration is a $50 \mathrm{~kW}$ model. The profile of wind speed data is plotted in Figure 3.

\footnotetext{
${ }^{1}$ http://N4E.LBL.gov
} 
International Journal of Computer Science \& Information Technology (IJCSIT) Vol 5, No 2, April 2013

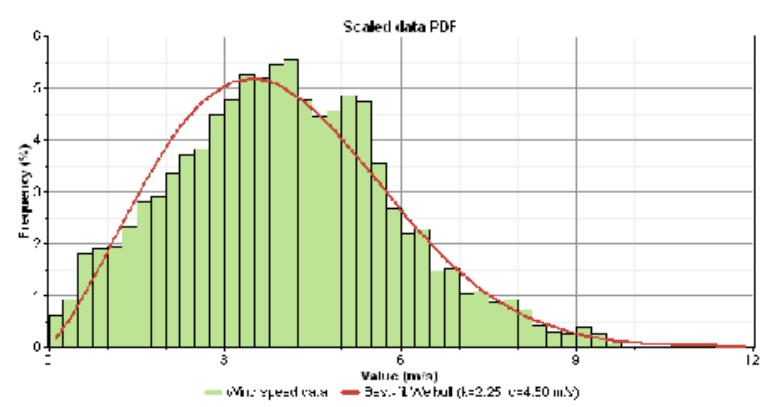

Figure 3: Profile of wind speed data.

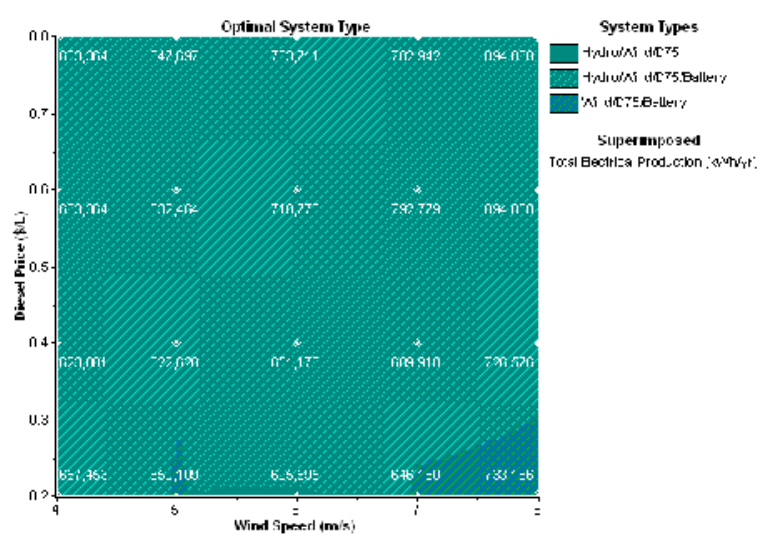

Figure 4: Total electricity production.

We considered a range of diesel fuel prices and wind speeds. The optimal system type graph shows that for high wind speeds and high fuel prices, wind power does make sense. Figure 4 shows total electricity production in terms of diesel price and wind speed. Figure 5 depicts fuel costs. Also, the HOMER software recommends a battery bank to capture excess wind power at the higher wind speeds.

Moreover, $\mathrm{CO}$ emissions for the optimal system type is plotted in Figure 6 in terms of wind speed and diesel costs. $75 \mathrm{~kW}$ diesel capacity is also shown in Figure 7.

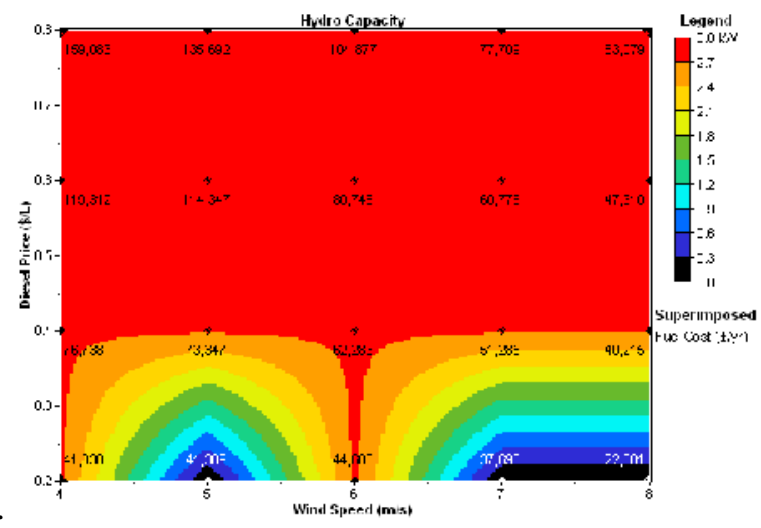

Figure 5: Fuel costs. 


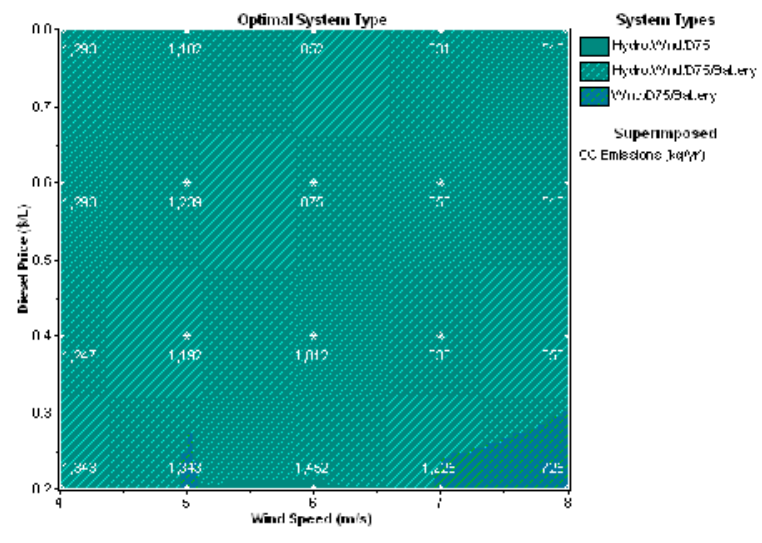

Figure 6: CO emissions.

For the simulation purposes, twelve average wind speed values are entered: one for each month of the year. The synthesized data sequence has the specified seasonal and daily patterns, as well as the specified Weibull distribution and autocorrelation.

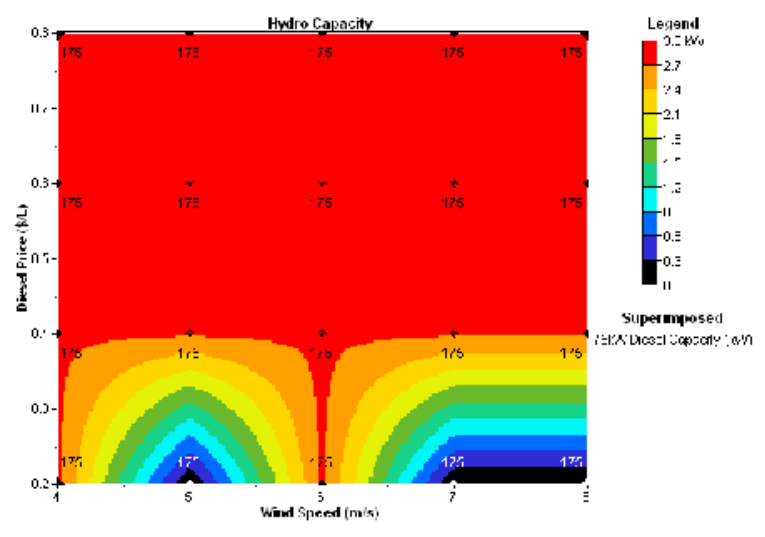

Figure 7: 75kW diesel capacity.

\section{FORECASTS OF FUTURE ELECTRICITY CONSUMPTION}

Figure 8 shows development of the number of internet users in Germany. Prof. Dr. Martin Faulstich Chairman of the Council of Environmental Advisors (SRU) from Germany called on the Federal Government that it promotes the conversion of the energy system. In his estimation, Germany can until 2020 - to be climate-friendly 100 percent supplied by renewable energies.

Due to ongoing climate change and forthcoming fossil-fuel shortage, the worldwide demand for clean renewable energy has been rapidly increasing in the past few years. Among different sustainable energy resources, wind energy is widely available and has become one of the most important solutions for energy crisis. Based on national policy benefits and wind industry innovations, in several countries, wind energy production has achieved relatively high levels of penetration. For example, Germany has invested to produce the electricity from renewable technologies since the beginning of this century. To this aim, Germany has more than doubled its renewable electricity production since 2000 and has already significantly exceeded its minimum target of $12.5 \%$ set for 2010 . This increase is achieved in expense of conventional electricity production, whereby nuclear power experienced the largest relative loss between. Currently, there 
is a high interest in wind power technology to produce the electricity. In 2008, the estimated share of wind power in Germany's electricity production amounted to $6.3 \%$, followed by biomassbased electricity generation and water power, whose shares were around $3.6 \%$ and $3.1 \%$, respectively.

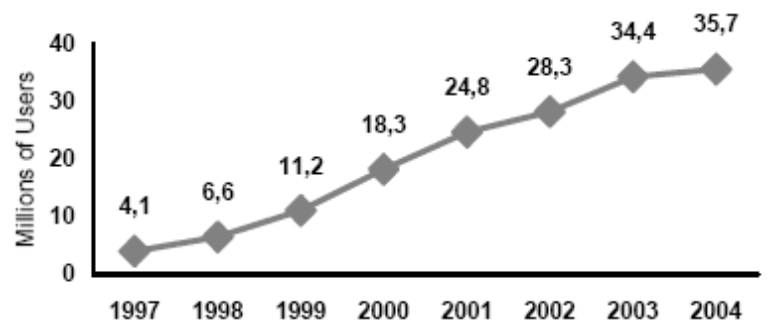

Figure 8. Development of the number of Internet users in Germany [18].

The German EEG is a start for the future which is also from other countries around the world have been taken as positive. The Federal Environment Ministry confirmed the 47 countries of the world use the EEG as a role model for your own funding opportunities. Subsequently, companies in Germany as bright spot recorded 20,000 new customers from Hamburg. It should be mentioned that it is particularly difficult to forecast trends in the IT industry.

The IDC forecast incorporates several trends that will affect power used by servers, including the move to more use of blade servers (which will tend to increase power use), and the shift to consolidation and virtualization (which will tend to decrease power use by reducing the number of physical servers that are needed). The industry has recently become more sensitive to total cost of ownership for these facilities, driven by the increasing importance of infrastructure and utility costs relative to IT costs ([1]).

\section{Conclusions}

In this paper, the World Wide Web and the rise of servers and PC's data centers are studied as a major position in the overall power consumption of the world. In order to prevent global warming and ensuing disasters, already Internet-service providers, hosting providers on green power have changed. Even household energy suppliers offer green electricity from renewable energy such as wind, solar, biomass and hydro, which emits no carbon dioxide, to stand against global warming. Only a global change for the area information technology can prevent the global-warming. The switch to renewable energy is the beginning of our future and must be pursued as well as the research and development in information and communication technology.

\section{ACKNOWLEDGEMENTS}

The authors gratefully acknowledge support from Hadori UG, www.hadori.de, Bremen, Germany. 
International Journal of Computer Science \& Information Technology (IJCSIT) Vol 5, No 2, April 2013

\section{REFERENCES}

[1] Brill, Kenneth G. 2007. Data Center Energy Efficiency and Productivity. Santa Fe, NM: The Uptime Institute. (http://www.upsite.com/cgibin/admin/admin.pl?admin=view_whitepapers)

[2] Brill, Kenneth G. 2007b. High-Density Computing: The Path Foward 2006. Santa Fe, NM: The Uptime Institute. (http://www.upsite.com/cgibin/admin/admin.pl?admin=view_whitepapers)

[3] Harris, Jeff, J. Roturier, L.K. Norford, and A. Rabl. 1988. Technology Assessment: Electronic Office Equipment. Lawrence Berkeley Laboratory. LBL-25558. November.

[4] Huber, Peter, and Mark P. Mills. 1999. "Dig more coal—the PCs are coming." In Forbes. May 31. pp. 70-72.

[5] Johnson, Brian J., and Catherine R. Zoi. 1992. "EPA Energy Star Computers: The Next Generation of Office Equipment." In Proceedings of the 1992 ACEEE Summer Study on Energy Efficiency in Buildings. Edited by Asilomar, CA: American Council for an Energy Efficient Economy. pp. 6.1076.114 .

[6] Kawamoto, Kaoru, Jonathan Koomey, Bruce Nordman, Richard E. Brown, Maryann Piette, Michael Ting, and Alan Meier. 2002. "Electricity Used by Office Equipment and Network Equipment in the U.S." Energy-The International Journal (also LBNL-45917). vol. 27, no. 3. March. pp. 255-269.

[7] Koomey, Jonathan, Mary Ann Piette, Mike Cramer, and Joe Eto. 1996. "Efficiency Improvements in U.S. Office Equipment: Expected Policy Impacts and Uncertainties." Energy Policy. vol. 24, no. 12. December. pp. 1101-1110.

[8] Koomey, Jonathan, 2007. "ESTIMATING TOTAL POWER CO NUMPTION BY SERVERS IN THE U.S. AND THE WORLD" Final Report, Lawrence Berkeley National Laboratory and Consulting Professor, Stanford University.

[9] Ledbetter, M, and L. Smith. 1993. Guide to Ener-gy-Efficient Office Equipment. Washington, DC: American Council for an Energy-Efficient Economy.

[10] Lovins, Amory, and H. Heede. 1990. Electrici-ty-Saving Office Equipment. Competitek/Rocky Mountain Institute. September.

[11] Markoff, John, and Saul Hansell. 2006. "Hiding in Plain Sight, Google Seeks an Expansion of Power." The New York Times. New York, NY. June 14.

[12] Mitchell-Jackson, Jennifer, Jonathan Koomey, Michele Blazek, and Bruce Nordman. 2002. "National and Regional Implications of Internet Data Center Growth." Resources, Conservation, and Recycling (also LBNL-50534). vol. 36, no. 3. October. pp. 175-185.

[13] Mitchell-Jackson, Jennifer, Jonathan Koomey, Bruce Nordman, and Michele Blazek. 2003. "Data Center Power Requirements: Measurements From Silicon Valley." Energy-The International Journal (also LBNL-48554). vol. 28, no. 8. June. pp. 837 - 850.

[14] Norford, Les, A. Hatcher, Jeffrey Harris, Jacques Roturier, and O. Yu. 1990. "Electricity Use in Information Technologies." In Annual Review of Energy 1990. Edited by J. M. Hollander. Palo Alto, CA: Annual Reviews, Inc. pp. 423-53.

[15] Roth, Kurt, Fred Goldstein, and Jonathan Kleinman. 2002. Energy Consumption by Office and Telecommunications Equipment in Commercial Buildings--Volume I: Energy Consumption Baseline. Washington, DC: Prepared by Arthur D. Little for the U.S. Department of Energy. A.D. Little Reference no. 72895-00. January. (http://www.eren.doe.gov/buildings/documents)

[16] Ton, My, and Brian Fortenbery. 2005. Server Power Supplies. Berkeley CA: Report to Lawrence Berkeley National Laboratory by Ecos Consulting and EPRI Solutions. December.

[17] UK Energy Research Centre, A REVIEW OF ELECTRICITY UNIT COST ESTIMATES Working Paper, December 2006 - Updated May 2007, available at: http://www.ukerc.ac.uk/Downloads/PDF/07/0706_TPA_A_Review_of_Electricity.pdf

[18] Bode, Sven; Groscurth, Helmuth-Michael, The Effect of the German Renewable Energy Act (EEG) on the Electricity Price?, HWWA Discussion Paper, No. 358, http://hdl.handle.net/10419/19388. 